\title{
Características de Carcaça e da Carne de Novilhas Charolês e 3/4 Charolês 1/4 Nelore, Terminadas em Confinamento
}

\author{
João Restle ${ }^{1}$, Liliane Cerdótes ${ }^{2}$, Fabiano Nunes Vaz ${ }^{3}$, Ivan Luiz Brondani ${ }^{4}$
}

\begin{abstract}
RESUMO - O objetivo deste trabalho foi estudar os aspectos quantitativos e qualitativos da carcaça e da carne de novilhas de descarte dos genótipos Charolês (C) e 3/4 C 1/4 Nelore (N). Foram usadas 25 novilhas de três anos, terminadas em confinamento por 80 dias. Não se verificou diferença para peso de abate $(473,6 \mathrm{vs} .468,8 \mathrm{~kg})$, peso de carcaça fria $(241,8 \mathrm{vs} .241,8 \mathrm{~kg})$, rendimento de carcaça fria ( 51,09 vs. $51,61 \%)$, espessura de gordura $(4,13$ vs. $4,78 \mathrm{~mm})$, porcentagem de dianteiro $(35,52 \mathrm{vs.} 36,01 \%)$ e de costilhar $(15,03$ vs. $15,42 \%)$, conformação (10,75 vs. 10,56 pontos) e comprimento de carcaça (127,4 vs. 129,9 cm). As novilhas C apresentaram maior porcentagem do corte serrote $(49,95$ vs. $48,57 \%)$ e perímetro de braço $(36,73$ vs. $35,00 \mathrm{~cm})$ que as $3 / 4 \mathrm{C} 1 / 4 \mathrm{~N}$. Não houve diferença significativa para a composição física da carcaça, cor (3,46 vs. 3,11 pontos), textura (3,67 vs. 3,33 pontos), marmoreio (6,40 vs. 5,00 pontos), maciez ( 6,48 vs. 6,19 pontos), palatabilidade (6,33 vs. 6,33 pontos) e força para corte das fibras da carne, por meio do aparelho WB-Shear (5,99 vs. 6,24 pontos). A suculência da carne foi melhor nas novilhas C (6,18 vs. 5,67 pontos). A partir desses resultados, pode-se concluir que, para novilhas abatidas aos três anos, não existem diferenças expressivas nos aspectos quantitativos e qualitativos da carcaça e da carne entre os dois genótipos.
\end{abstract}

Palavras-chave: características sensoriais, composição física da carcaça, cor da carne, cruzamento, fêmeas de descarte, marmoreio

\section{Carcass and Meat Characteristics of Charolais and 3/4 Charolais 1/4 Nellore Cull Heifers, Finished in Feedlot}

\begin{abstract}
The objective of this work was to study the quantitative and qualitative carcass and meat characteristics of Charolais (C) and 3/4 C 1/4 Nellore (N) cull heifers. Twenty-five culled heifers, three years old, were feedlot finished per 80 days period. No significant difference was observed for slaughter weight ( $473.6 \mathrm{vs} .468 .8 \mathrm{~kg}$ ), cold carcass weight ( $241.8 \mathrm{vs} .241 .8 \mathrm{~kg}$ ), dressing percentage ( 51.09 vs. $51.61 \%)$, fat thickness ( 4.13 vs. $4.78 \mathrm{~mm}$ ), forequarter percentage (35.52 vs. $36.01 \%)$, sidecut percentage ( $15.03 \mathrm{vs.} 15.42 \%)$, conformation (10.75 vs. 10.56 points) and carcass length $(127.4$ vs. $129.9 \mathrm{~cm})$. The $\mathrm{C}$ heifers showed higher sawcut $(49.45 \mathrm{vs.} 48.57 \%)$ and arm perimeter $(36.73 \mathrm{vs} .35 .00 \mathrm{~cm}$ ) than the $3 / 4 \mathrm{C} 1 / 4 \mathrm{~N}$ heifers. No significant difference was observed for carcass composition, meat color ( $3.46 \mathrm{vs} .3 .11$ points), texture ( $3.67 \mathrm{vs} .3 .33$ points), marbling ( $6.40 \mathrm{vs} .5 .00$ points), tenderness (6.48 vs. 6.19 points), flavor (6.33 vs. 6.33 points) and WB-Shear value ( 5.99 vs. $6.24 \mathrm{~kg}$ ). Meat juiciness was higher for C heifers (6.18 vs. 5.67 points). For heifers slaughtered at three years of age, no expressive differences for quantitative and qualitative carcass and meat aspects were observed between the two genotypes.
\end{abstract}

Key Words: carcass physical composition, crossbreeding, culled females, marbling, meat color, sensorial characteristics

\section{Introdução}

No grupo das raças de corte de origem européia, a Charolês (C) é a raça continental mais criada no Rio Grande do Sul, devido às suas características de velocidade de crescimento e alto peso ao abate. Considerando-se todo o território brasileiro, a raça Nelore (N) é a mais criada e, nos últimos anos, tem sido a mais utilizada no cruzamento com as raças européias no Sul do Brasil.
Assim como as raças zebuínas têm obtido boa aceitação no Sul, as raças taurinas também são bem aceitas no centro do país para o cruzamento com Nelore. Segundo KOGER (1980), a razão desse sucesso é o alto nível de heterose originária da grande distância genética existente entre os grupos Bos taurus e Bos indicus. VAZ (1999), ao estudar as características de carcaça de animais cruzados, observou altos valores de heterose total em animais da segunda geração de cruzamento alternado $\mathrm{C}$ x N. No

\footnotetext{
1 Engenheiro-Agrônomo, PhD, Professor Titular do Departamento de Zootecnia - UFSM, Pesquisador do CNPq - Campus de Camobi, CEP: 97.119-105, Santa Maria - RS. E.mail: jorestle@ccr.ufsm.br

2 Aluna de Graduação do curso de Zootecnia.

3 Zootecnista, MS, Projepec Consultores Associados Ltda.

4 Zootecnista, MS, Professor Assistente do Departamento de Zootecnia.
} 
mesmo trabalho, constatou indícios fortes da manifestação da heterose materna nas características de carcaça e da carne de novilhos com genótipo 3/4 abatidos aos dois anos. Esses resultados, assim como os de outros trabalhos (PEROTTO et al., 1999), mostraram que, mesmo quando o cruzamento alternado alcança os valores mínimos de heterose individual (animais 3/4), existe a compensação pela heterozigose materna (mãe 1/2), que atinge seu valor máximo (100\%).

Há alguns anos, devido à falta de qualidade ofertada ao consumidor brasileiro, o consumo de carne bovina vem perdendo espaço para as aves e suínos. A melhoria da qualidade da carne bovina passa pela redução da idade de abate dos animais. Para isso, pode-se explorar o vigor híbrido dos cruzamentos, principalmente aqueles que envolvem bovinos das raças zebuínas com raças européias, obtendo, dessa forma, animais com maior velocidade de crescimento, chegando mais cedo ao abate (RESTLE et al., 1995a).

Por existirem poucos trabalhos brasileiros que comparam fêmeas de descarte para produção de carne (RESTLE et al., 1990; PEROBELLI et al., 1994, 1995; JUNQUEIRA et al., 1998), mesmo que grande parte da carne ofertada no mercado seja oriunda desses animais, o objetivo deste trabalho foi de estudar as características da carcaça e da carne de novilhas de descarte do genótipo 3/4 C 1/4 N, em comparação com a raça $\mathrm{C}$ definida.

\section{Material e Métodos}

A terminação dos animais foi realizada no Setor de Bovinocultura de Corte do Departamento de Zootecnia da Universidade Federal de Santa Maria - RS.

Foram utilizadas 25 novilhas de descarte, com três anos de idade, dos genótipos C e 3/4 C 1/4 N, nascidas no ano de 1996. As fêmeas foram mantidas desde o nascimento nas mesmas condições de manejo e alimentação. As fêmeas foram produzidas em um sistema que utiliza a inseminação artificial (período de 45 dias) e a monta natural (período de 45 dias). Os touros $\mathrm{C}$ que geraram as novilhas $\mathrm{C}$ foram os mesmos progenitores das fêmeas $3 / 4 \mathrm{C} 1 / 4 \mathrm{~N}$. Os animais foram alimentados por 80 dias em confinamento com uma dieta composta por $65 \%$ de silagem de sorgo (AG 2002) $+35 \%$ de concentrado (base da matéria seca), composto à base de casca de soja, farelo de arroz integral, farelo de soja e minerais. O teor de proteína bruta médio da dieta foi de $12 \%$.

Os animais foram abatidos com idade média de
36 meses. O peso de fazenda foi tomado antes do embarque para o abatedouro, obedecendo um jejum de sólidos de 12 horas. Os animais foram abatidos em matadouro comercial, seguindo-se o fluxo normal do estabelecimento. Após o abate, as carcaças dos animais foram identificadas antes de entrar para a câmara de resfriamento. As carcaças foram resfriadas por 24 horas a $-2^{\circ} \mathrm{C}$ e, após, foi medido o peso de carcaça fria, avaliadas a conformação e a maturidade fisiológica da carcaça e efetuadas as medidas de desenvolvimento da carcaça, seguindo-se a metodologia sugerida por MULLER (1987).

A medida da porcentagem de dianteiro, costilhar e serrote foi realizada por meio da separação destes cortes, pesagem e posterior cálculo da porcentagem destes em relação ao peso de meia carcaça. A área de Longissimus dorsi foi medida na altura da $12^{\mathrm{a}}$ costela, onde mensurou-se a área desse músculo realizando-se um corte perpendicular ao comprimento do mesmo. Nesse mesmo corte foi medida a espessura de gordura subcutânea.

A composição física da carcaça foi medida pela técnica sugerida por HANKINS e HOWE (1946), sendo que a porção de Longissimus dorsi extraída da amostra usada na técnica foi embalada, identificada e levada para o congelamento, sendo posteriormente utilizada para avaliação das características sensoriais da carne e a força necessária para o cizalhamento das fibras, por intermédio do aparelho WB-Shear.

O delineamento experimental foi o inteiramente casualizado, com número diferente de repetições por tratamento. Os resultados foram submetidos à análise de variância e "Teste F", a $10 \%$ de significância. Todas as características de interesse econômico foram analisadas utilizando-se o seguinte modelo estatístico:

$$
\mathrm{Y}_{\mathrm{ij}}=\mu+\mathrm{G}_{\mathrm{i}}+\mathrm{e}_{\mathrm{ij}}
$$

em que: $Y_{i j}$ representa a observação realizada no j-ésimo animal, pertencente ao i-ésimo genótipo; $\mu$, a média geral da característica; $G_{i}$, o efeito do i-ésimo genótipo; $\mathrm{e}_{\mathrm{ij}}$, o efeito residual, associado à observação realizada no j-ésimo animal.

\section{Resultados e Discussão}

Na Tabela 1 são apresentados os resultados referentes ao peso de abate, de carcaça, rendimento de carcaça, espessura de gordura e porcentagem dos cortes comerciais.

Observa-se na Tabela 1 que não houve diferença $(\mathrm{P}>0,10)$ para o peso de abate $(\mathrm{C}=473,6 \mathrm{~kg}$ e $3 / 4 \mathrm{C}$ 
$1 / 4 \mathrm{~N}=468,8 \mathrm{~kg}$ ) e de carcaça fria (C e $3 / 4 \mathrm{C} 1 / 4 \mathrm{~N}=$ $241,8 \mathrm{~kg}$ ) entre os dois grupos genéticos. No presente estudo, o que diferencia os dois grupos de animais é o grupo genético das novilhas e de suas mães. No primeiro caso, pode-se esperar um efeito de heterose individual nas novilhas cruzadas. Provavelmente, o efeito da heterose tenha sido positivo para essa característica, que, segundo VAZ (1999), é de 10,10\% na $\mathrm{G} 2$, entretanto, nas novilhas cruzadas do presente trabalho, existe um efeito genético aditivo da raça $\mathrm{N}$, que nas novilhas puras $\mathrm{C}$ não existe $\mathrm{e}$, nos animais da raça $\mathrm{N}$, propicia menor peso de abate nos animais cruzados, quando comparados com a raça C. Os trabalhos de pesquisa que comparam a raça $\mathrm{C}$ e raças zebuínas têm demonstrado que o efeito genético aditivo da raça $\mathrm{C}$ é superior ao das raças Bos indicus para o peso de abate (PEACOCK et al., 1979; DeROUEN et al., 1992). Em seu trabalho, VAZ (1999) verificou, em novilhos pertencentes ao mesmo projeto de pesquisa, peso de abate um pouco inferior nos C em relação aos 3/4 C 1/4 N (457 vs. 468 kg). O que provavelmente acontece é que existe um efeito de heterose materna que pode ser observado aos 24 meses de idade, conforme foi discutido no trabalho de VAZ (1999), que aos três anos (idade de abate das novilhas do presente trabalho) não é mais constatado, pois os animais $C$ continuam crescendo, compensando o menor desenvolvimento que obtém até os 24 meses, em relação aos cruzados. Esse efeito pode ser observado também no peso de carcaça fria, pois os novilhos utilizados por VAZ (1999) apresentaram peso de carcaça fria de 239 e $251 \mathrm{~kg}$, respectivamente, para C e 3/4 C $1 / 4 \mathrm{~N}$, e no presente estudo o peso foi de $241,8 \mathrm{~kg}$ para ambos os grupos genéticos.

Também com animais abatidos aos 24 meses, RESTLE et al. (1999) verificaram que, mesmo em animais com elevado grau de sangue $\mathrm{N}(75 \%)$, o peso de carcaça foi de $207 \mathrm{~kg}$, contra $199 \mathrm{~kg}$ nos animais Hereford (H) puros. FLORES (1997), abatendo machos inteiros aos quatorze meses, verificou que o peso de carcaça quente foi de $240 \mathrm{~kg}$ nos animais $3 / 4 \mathrm{H} 1 / 4 \mathrm{~N}$ e $236 \mathrm{~kg}$ nos animais $\mathrm{H}$.

Também o rendimento de carcaça fria foi semelhante $(\mathrm{P}>0,10)$ entre os dois grupos genéticos, mostrando que o efeito genético aditivo da raça $\mathrm{N}$ para incremento no rendimento de carcaça não foi o bastante para propiciar maior rendimento nas novilhas cruzadas, conforme outros trabalhos que comparam o rendimento de carcaça da raça $\mathrm{N}$ com raças européias (PEROBELLI et al., 1995; RESTLE et al., 1995a; MOLETTA e RESTLE, 1996a; WHEELER et al., 1996; RESTLE et al., 1999). Em seu estudo, FLORES et al. (1999) observaram rendimento de carcaça fria superior em animais $3 / 4 \mathrm{H} 1 / 4 \mathrm{~N}(54,1 \%)$ em relação aos machos $\mathrm{H}(52,7 \%)$.

Observa-se, na Tabela 2, que os dois genótipos de novilhas não diferiram na espessura de gordura, sendo de 4,13 mm nas $\mathrm{C}$ e 4,78 $\mathrm{mm}$ nas $3 / 4 \mathrm{C} 1 / 4 \mathrm{~N}$. A espessura de gordura esteve estreitamente correlacionada com o peso de carcaça dos animais, sendo que a correlação entre essas duas variáveis foi de $0,70(\mathrm{P}<0,01)$ nas novilhas $\mathrm{C}$ e $0,84(\mathrm{P}<0,01)$ nas

Tabela 1 - Média e desvio-padrão (DP) para pesos de abate e carcaça, rendimento de carcaça, espessura de gordura e percentagem dos cortes comerciais

Table 1 - Mean and standard error (DP) for slaughter and carcass weight, carcass dressing, fat thickness and commercial cuts percentages

\begin{tabular}{|c|c|c|c|c|c|}
\hline \multirow{2}{*}{$\begin{array}{l}\text { Característica } \\
\text { Characteristic }\end{array}$} & \multicolumn{2}{|c|}{$\mathrm{C}$} & \multicolumn{2}{|c|}{$3 / 4 \mathrm{C} 1 / 4 \mathrm{~N}$} & \multirow[t]{2}{*}{$\mathrm{P}$} \\
\hline & $\begin{array}{l}\text { Média } \\
\text { Mean }\end{array}$ & $\mathrm{DP}$ & $\begin{array}{l}\text { Média } \\
\text { Mean }\end{array}$ & DP & \\
\hline $\begin{array}{l}\text { Peso de abate, } \mathrm{kg} \\
\text { Slaughter weight, } \mathrm{kg}\end{array}$ & 473,6 & 9,3 & 468,8 & 12,4 & 0,7610 \\
\hline $\begin{array}{l}\text { Peso de carcaça fria, } \mathrm{kg} \\
\text { Cold carcass weight, } \mathrm{kg}\end{array}$ & 241,8 & 4,7 & 241,8 & 6,2 & 0,9965 \\
\hline $\begin{array}{l}\text { Rendimento de carcaça fria, } \% \\
\text { Dressing percentage, } \%\end{array}$ & 51,09 & 0,42 & 51,61 & 0,56 & 0,4639 \\
\hline $\begin{array}{l}\text { Espessura de gordura, mm } \\
\text { Fat thickness, } \mathrm{mm}\end{array}$ & 4,13 & 0,33 & 4,78 & 0,43 & 0,2467 \\
\hline $\begin{array}{l}\text { Dianteiro, } \% \\
\text { Forequarter, } \%\end{array}$ & 35,52 & 0,22 & 36,01 & 0,30 & 0,2008 \\
\hline $\begin{array}{l}\text { Costilhar, \% } \\
\text { Sidecut, \% }\end{array}$ & 15,03 & 0,18 & 15,42 & 0,24 & 0,2089 \\
\hline $\begin{array}{l}\text { Serrote, } \% \\
\text { Sawcut, } \%\end{array}$ & 49,45 & 0,28 & 48,57 & 0,37 & 0,0674 \\
\hline
\end{tabular}


cruzadas (Tabelas 3 e 4). VAZ (1999) observou 2,2 e $2,8 \mathrm{~mm}$, respectivamente, para novilhos $\mathrm{C}$ e $3 / 4 \mathrm{C}$ $1 / 4 \mathrm{~N}$, abatidos aos dois anos de idade.

Observando os resultados para porcentagem dos cortes comerciais (Tabela 1), verifica-se que a porcentagem de dianteiro e de costilhar não diferiram entre os dois grupos de novilhas. Comparando machos $\mathrm{N}$ e cruzas $\mathrm{N}$ x Canchim, LUCHIARI FILHO et al. (1989) não verificaram diferença no percentual de dianteiro e costilhar entre esses genótipos. Estudando novilhos Hereford e suas cruzas com N, RESTLE et al. (1999) não verificaram diferença na porcentagem de dianteiro e costilhar, entre animais que possuíam $0,32,50$ ou $75 \%$ de sangue $\mathrm{N}$ no genótipo.

Embora não tenha existido diferença na porcentagem de dianteiro e costilhar, a porcentagem de serrote foi maior $(\mathrm{P}=0,0674)$ nas novilhas $\mathrm{C}(49,45 \%)$ em relação às $3 / 4 \mathrm{C} 1 / 4 \mathrm{~N}(48,57 \%)$. Os resultados referentes à porcentagem dos cortes comerciais da carcaça apresentados na Tabela 1 parecem comprovar que a raça $\mathrm{C}$ apresenta maior desenvolvimento do trem posterior, quando comparada com animais que possuem sangue $\mathrm{N}$ no genótipo. Esses resultados são confirmados ao observar-se os resultados de PEROBELLI et al. (1995), que, ao trabalharem com vacas de descarte, verificaram maior porcentagem de serrote nas vacas $\mathrm{C}(51,12 \%)$ em relação às vacas N (49,48\%). Também MOLETTA e RESTLE (1996a) verificaram que os novilhos $\mathrm{C}$ apresentaram maior porcentagem de serrote que os N. Estudando novilhos C e 3/4 C 1/4 N, VAZ (1999) verificou porcentagem de serrote de 49,9 e $49,5 \%$, respectivamente, para C e 3/4 C 1/4 N. Outros autores têm relatado a grande aptidão que a raça $\mathrm{C}$ apresenta para o desenvolvimento muscular da carcaça, ao medirem as características como a conformação de carcaça, cujos resultados do presente estudo são apresentados na Tabela 4 .

$\mathrm{Na}$ Tabela 4, observa-se que não houve diferença $(\mathrm{P}>0,10)$ para a conformação de carcaça entre os dois genótipos avaliados. Nos dois genótipos, as carcaças apresentaram conformação entre boa menos (10) e boa típica (11). Resultados similares foram verificados no trabalho realizado por RESTLE et al. (1995b), quando avaliaram novilhos das raças $\mathrm{C}, \mathrm{N}$ e suas respectivas cruzas. Nesse experimento os autores observaram 10,8 pontos para conformação de carcaça nos novilhos $C, 1 / 2$ C $1 / 2 \mathrm{~N}$ e $1 / 2 \mathrm{~N} 1 / 2 \mathrm{C}$. RESTLE et al. (1995b) relataram que, embora a conformação tenha sido similar entre os animais $\mathrm{C}$ e os novilhos $1 / 2$ sangue, a heterose na $F_{1}$ foi de $10,77 \%$, pois foi verificado nos animais $\mathrm{N}$ um valor para conformação de carcaça inferior aos $\mathrm{C}$, ou seja, 8,7 pontos.

Verifica-se no presente estudo que a inclusão de sangue $\mathrm{N}$ no genótipo das novilhas não afetou a conformação de carcaça. Esse resultado deve-se, provavelmente, à heterose compensando o efeito aditivo da raça $\mathrm{N}$, o qual tende a piorar a conformação de carcaça nos cruzamentos com raças de boa aptidão para essa característica, como é o caso da $C$.

A característica comprimento de carcaça (Tabela 4) foi similar entre as novilhas $\mathrm{Ce} 3 / 4 \mathrm{C} 1 / 4 \mathrm{~N}(\mathrm{P}>0,10)$. Nas novilhas $C$, a correlação entre comprimento e peso de carcaça foi de $0,70(\mathrm{P}<0,01)$; também nas novilhas $3 / 4 \mathrm{C} 1 / 4 \mathrm{~N}$, foi observada correlação estreita entre rendimento de carcaça fria e comprimento de carcaça, sendo $0,83(\mathrm{P}<0,01)$.

Trabalhando com diferentes genótipos de bovinos, MOLLETA e RESTLE (1996a) verificaram 124,5 cm de comprimento de carcaça nos novilhos Ce 119,2 cm nos N. Resultados que mostram maior comprimento de carcaça em animais $\mathrm{C}$ em relação aos $\mathrm{N}$ também são citados por outros autores em trabalhos conduzidos com vacas de descarte (PEROBELLI et al., 1995).

Estudando diferentes graus de sangue no cruzamento entre Hereford e N, FLORES (1997) e RESTLE et al. (1999) constataram que o incremento de sangue $\mathrm{N}$ no cruzamento aumenta as medidas das pernas e braços dos animais. No presente trabalho, observa-se que as novilhas cruzadas não diferiram $(\mathrm{P}>0,10)$ das $\mathrm{C}$ nestas características (Tabela 4). Estudando o cruzamento entre novilhos $\mathrm{C}$ e $\mathrm{N}$ pertencentes ao mesmo projeto de pesquisa das novilhas relatadas neste trabalho, VAZ (1999) verificou que a porcentagem de $25 \%$ de $\mathrm{N}$ no genótipo acarreta em carcaças e membros semelhantes no comprimento, quando comparados com novilhos $\mathrm{C}$ puros.

Constam da Tabela 4 também duas características importantes no que diz respeito à musculosidade da carcaça, à espessura de coxão e ao perímetro de braço. Observa-se, nesta Tabela, que as fêmeas não diferiram na espessura de coxão, mas as $\mathrm{C}$ apresentaram maior perímetro de braço $(36,73 v s .35,00 \mathrm{~cm}$; $\mathrm{P}=0,0053)$ que as cruzadas, mostrando o efeito do sangue $\mathrm{N}$ no genótipo, conforme foi verificado em outros estudos que compararam animais $\mathrm{C}$ e $\mathrm{N}$ (RESTLE et al., 1995a; MOLETTA e RESTLE, 1996a), em que animais $\mathrm{N}$ apresentam menor espessura de coxão e perímetro de braço que os animais europeus. Na Tabela 5 são apresentados os resultados referentes à composição física da carcaça. 


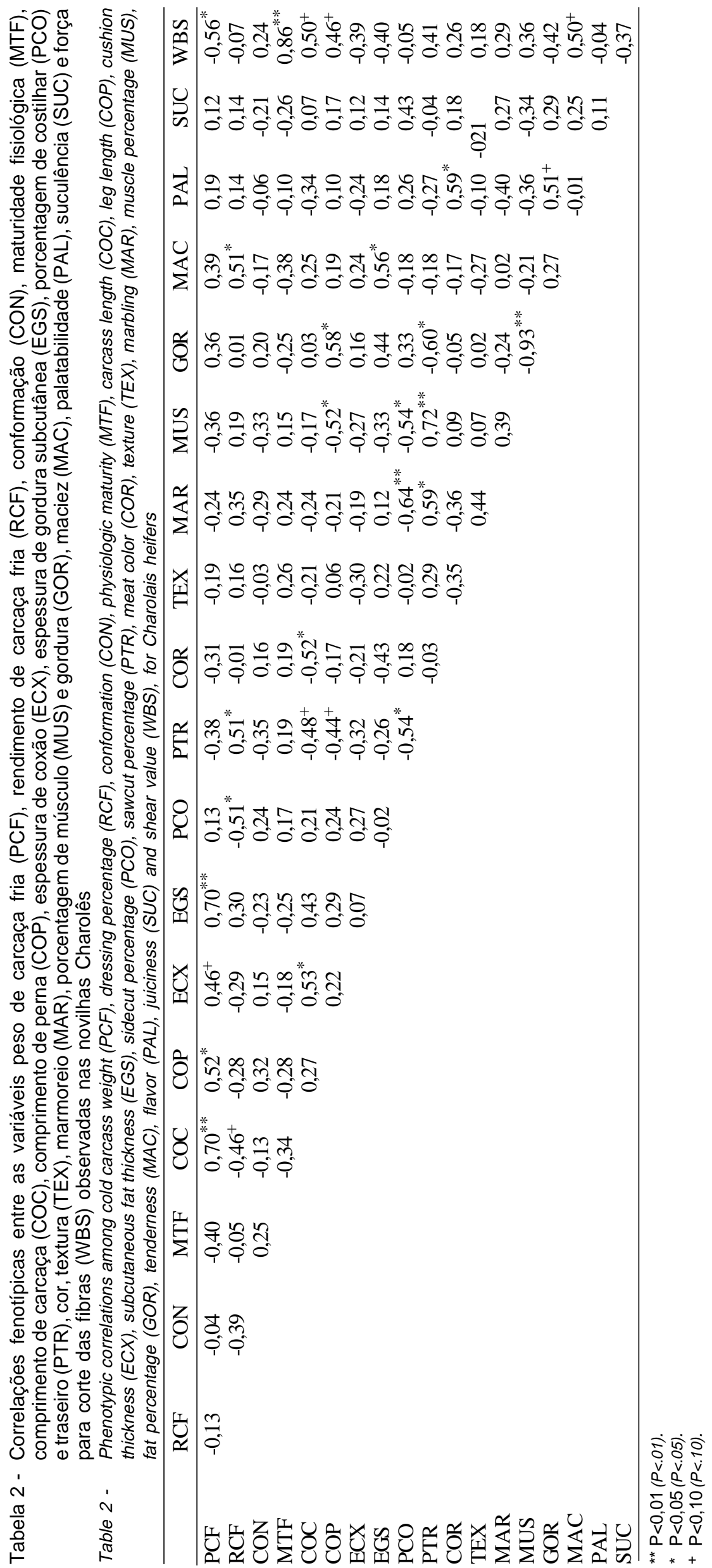




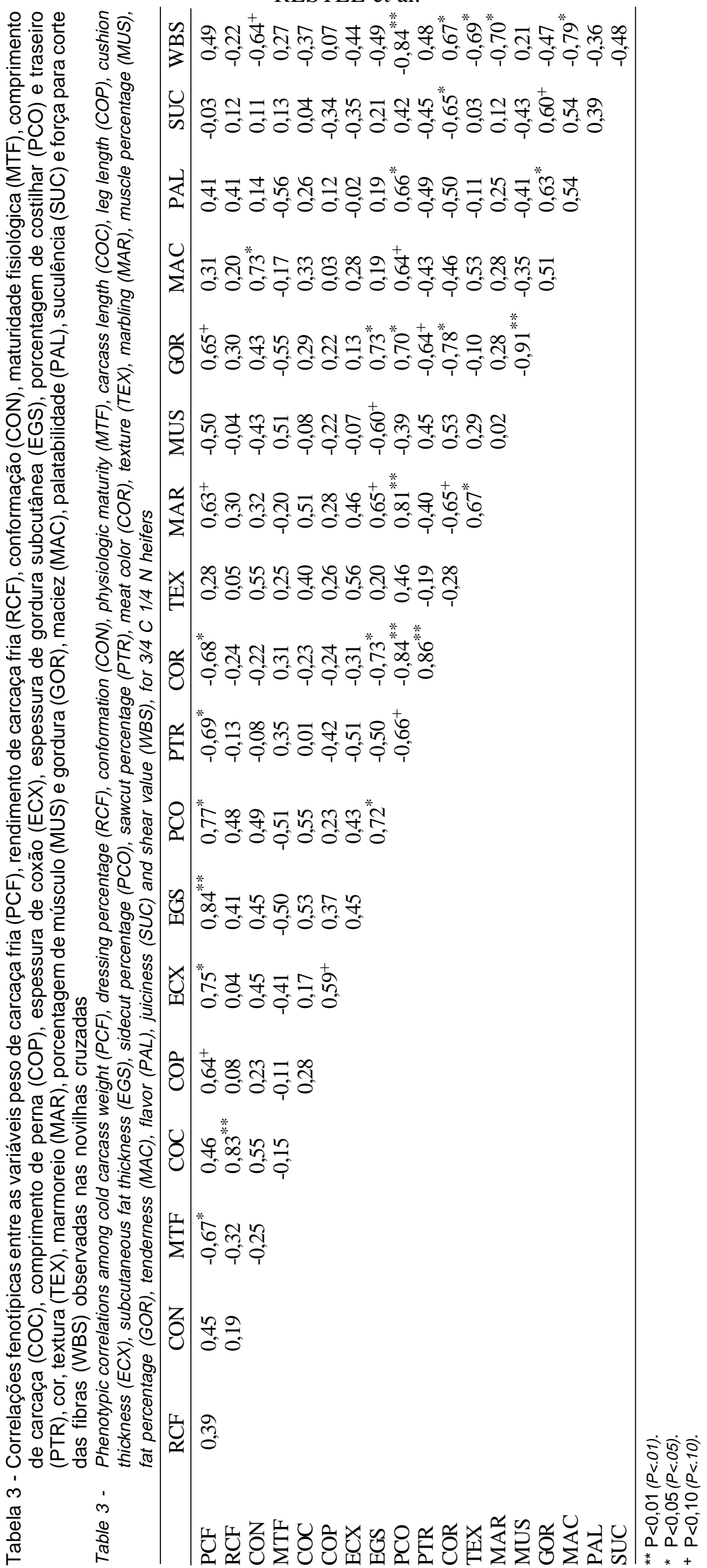


Rev. bras. zootec.

Tabela 4 - Média e desvio-padrão (DP) para conformação, maturidade fisiológica e medidas de desenvolvimento da carcaça Table 4 - Mean and standard error (DP) for conformation, maturity and growth measures of the carcasses

\begin{tabular}{|c|c|c|c|c|c|}
\hline \multirow{2}{*}{$\begin{array}{l}\text { Característica } \\
\text { Characteristic }\end{array}$} & \multicolumn{2}{|c|}{$\mathrm{C}$} & \multicolumn{2}{|c|}{$3 / 4 \mathrm{C} 1 / 4 \mathrm{~N}$} & \multirow[t]{2}{*}{$\mathrm{P}$} \\
\hline & $\begin{array}{l}\text { Média } \\
\text { Mean }\end{array}$ & $\mathrm{DP}$ & $\begin{array}{l}\text { Média } \\
\text { Mean }\end{array}$ & $\mathrm{DP}$ & \\
\hline Conformação, pontos 1 & 10,75 & 0,14 & 10,56 & 0,19 & 0,4135 \\
\hline $\begin{array}{l}\text { Conformation, score } \\
\text { Maturidade fisiológica, pontos }\end{array}$ & 11,25 & 0,22 & 10,78 & 0,30 & 0,2197 \\
\hline $\begin{array}{l}\text { Physiologic maturity, score } \\
\text { Comprimento de carcaça, } \mathrm{cm} \\
\text { Carcass length, } \mathrm{cm}\end{array}$ & 127,4 & 1,5 & 129,9 & 1,9 & 0,3194 \\
\hline $\begin{array}{l}\text { Comprimento de perna, } \mathrm{cm} \\
\text { Leg length, } \mathrm{cm}\end{array}$ & 74,00 & 0,46 & 74,89 & 0,60 & 0,2528 \\
\hline $\begin{array}{l}\text { Espessura de coxão, cm } \\
\text { Cushion thickness, } \mathrm{cm}\end{array}$ & 25,43 & 0,34 & 25,83 & 0,44 & 0,4805 \\
\hline $\begin{array}{l}\text { Comprimento de braço, } \mathrm{cm} \\
\text { Arm length, } \mathrm{cm}\end{array}$ & 37,10 & 0,24 & 37,33 & 0,31 & 0,5534 \\
\hline $\begin{array}{l}\text { Perímetro de braço, } \mathrm{cm} \\
\text { Arm perimeter, } \mathrm{cm}\end{array}$ & 36,73 & 0,34 & 35,00 & 0,44 & 0,0053 \\
\hline
\end{tabular}

Os resultados mostrados na tabela anterior indicam que os dois genótipos foram semelhantes na porcentagem de músculo e gordura na carcaça $(\mathrm{P}>0,10)$. À medida que se elevou o percentual de músculo nas novilhas $\mathrm{C}$, também aumentou o percentual de traseiro, o que é confirmado por intermédio do coeficiente de correlação entre estas variáveis, o qual foi de $0,72(\mathrm{P}<0,01)$. GALVÃO et al. (1991), estudando novilhos machos não castrados de três grupos genéticos, $\mathrm{N}, \mathrm{F}_{1}$ Nelore $\mathrm{x}$ Marchigiana e $F_{1}$ Nelore $x$ Limousin, verificaram que a porcentagem de músculo na carcaça foi superior para os animais cruzados, em relação aos $\mathrm{N}$, ocorrendo o inverso na porcentagem de gordura na carcaça, ou seja, os novilhos $\mathrm{N}$ obtiveram maior percentual de gordura na carcaça $(28,37 \%)$ em relação aos cruzados Marchigiana $(24,37 \%)$ e Limousin $(23,22 \%)$. Maior deposição de músculo na carcaça é característico das raças continentais de grande porte, como é o caso da Limousin, da Marchigiana (GALVÃO et al., 1991) e da C (PEACOCK et al., 1979; DeROUEN et al., 1992).

MOLLETA e RESTLE (1996a) observaram maior percentagem de músculo na carcaça de novilhos C $(68,56 \%)$ em relação aos $\mathrm{N}(61,73 \%)$, os quais foram superiores na porcentagem de gordura $(22,88 \%)$ em relação à raça européia $(15,01 \%)$. Ao trabalharem com machos de uma raça britânica em cruzamento com a N, FLORES et al. (1999) não verificaram diferença na porcentagem de músculo de machos Hereford (H) e 3/4 H 1/4 N, sendo de 63,0 e 65,6\%, respectivamente. Entretanto, devido à necessidade da intensificação dos sistemas pecuários (VAZ et al., 1999), a utilização da raça C e outras continentais vem encontrando resistência entre os produtores que buscam a redução da idade ao abate dos animais, pois essa raça, por possuir grande velocidade de ganho de peso, mostra-se tardia na deposição de gordura, restringindo a comercialização de novilhos jovens. RESTLE et al. (1997), estudando novilhos C abatidos com diferentes pesos, aos três anos de idade, constataram que somente aos $495 \mathrm{~kg}$, e depois de 184 dias de terminação em confinamento, os animais apresentaram 19,4\% de gordura na carcaça, sendo que aos $461 \mathrm{~kg}$, esse percentual foi de 16,5 e aos $421 \mathrm{~kg}$, de $15,5 \%$. No presente trabalho, verifica-se que, mesmo sem diferença estatística, houve leve superioridade, de quase um ponto percentual, das novilhas cruzadas em relação às puras no teor de gordura da carcaça. Entretanto, observa-se também que as novilhas $\mathrm{C}$ deste estudo apresentaram, aos três anos de idade, um percentual de gordura adequado para a comercialização $(21,04 \%)$, atingido aos 473,6 kg (Tabela 1). Vale lembrar ainda que dois efeitos importantes são esperados na regulação do percentual de gordura da carcaça de bovinos, o nível alimentar e o sexo ou condição sexual (BERG e BUTTERFIELD, 1976).

A semelhança entre os dois grupos genéticos no percentual de osso e gordura fez com que não fosse verificada diferença significativa nas relações músculo/osso $(\mathrm{P}>0,10)$ e músculo + gordura/osso $(\mathrm{P}>0,10)$. GALVÃO et al. (1991) relatam em seu trabalho que, 
Tabela 5 - Média e desvio-padrão (DP) para composição física da carcaça e relações músculo/osso e músculo + gordura/osso Table 5 - Mean and standard error (DP) for carcass composition and muscle/bone and muscle + fat/bone relations

\begin{tabular}{|c|c|c|c|c|c|}
\hline \multirow{2}{*}{$\begin{array}{l}\text { Característica } \\
\text { Characteristic }\end{array}$} & \multicolumn{2}{|c|}{$\mathrm{C}$} & \multicolumn{2}{|c|}{$3 / 4 \mathrm{C} 1 / 4 \mathrm{~N}$} & \multirow[t]{2}{*}{$\mathrm{P}$} \\
\hline & $\begin{array}{l}\text { Média } \\
\text { Mean }\end{array}$ & DP & $\begin{array}{l}\text { Média } \\
\text { Mean }\end{array}$ & $\mathrm{DP}$ & \\
\hline $\begin{array}{l}\text { Músculo na carcaça, \% } \\
\text { Muscle, \% }\end{array}$ & 65,03 & 0,50 & 64,10 & 0,67 & 0,2775 \\
\hline $\begin{array}{l}\text { Gordura na carcaça, \% } \\
\text { Fat, \% }\end{array}$ & 21,04 & 0,59 & 22,03 & 0,79 & 0,3263 \\
\hline $\begin{array}{l}\text { Osso na carcaça, } \% \\
\text { Bone, } \%\end{array}$ & 14,46 & 0,19 & 14,39 & 0,25 & 0,8092 \\
\hline $\begin{array}{l}\text { Relação músculo/osso } \\
\text { Muscle/bone }\end{array}$ & 4,51 & 0,06 & 4,47 & 0,08 & 0,6862 \\
\hline $\begin{array}{l}\text { Relação músculo + gordura/osso } \\
\text { Muscle }+ \text { fat/bone }\end{array}$ & 5,97 & 0,09 & 6,01 & 0,12 & 0,8092 \\
\hline
\end{tabular}

os animais $\mathrm{N}$ definidos apresentaram menor relação músculo/osso que os animais $\mathrm{F}_{1} \mathrm{~N}$ x raças continentais. Em seu estudo, VAZ (1999) também verificou, em novilhos abatidos aos dois anos de idade, resultados bastante similares entre os genótipos C e $3 / 4 \mathrm{C} 1 / 4 \mathrm{~N}$, para essas duas características. No entanto, as médias para relação músculo/osso e músculo + gordura/ osso citadas por VAZ (1999) são bastante inferiores (3,57 e 4,48, respectivamente) às do presente estudo (4,49 e 5,99, respectivamente). A diferença pode ser atribuída à baixa porcentagem de osso verificada na carcaça das novilhas abatidas aos três anos, em comparação aos novilhos que foram abatidos aos dois anos. Prova disso são os resultados obtidos por RESTLE et al. (1997), quando novilhos abatidos aos três anos de idade apresentaram 13,5 e $13,3 \%$ de osso na carcaça, com peso de abate de 461 e $495 \mathrm{~kg}$, respectivamente, sendo a relação músculo/osso de 5,3 e 5,2 e a relação músculo + gordura/osso de 6,5 e 6,7 , citados na mesma ordem, resultados superiores aos verificados por VAZ (1999), pesquisando novilhos abatidos aos dois anos. Ao trabalhar com machos de uma raça britânica em cruzamento com a N, FLORES et al. (1999) não verificaram diferença na porcentagem de músculo de machos Hereford $(\mathrm{H})$ e $3 / 4 \mathrm{H} 1 / 4 \mathrm{~N}$, sendo de 63,0 e $65,6 \%$, respectivamente.

$\mathrm{Na}$ Tabela 6, são apresentados os resultados referentes às características subjetivas avaliadas na carne das novilhas. A coloração da carne, apresentada na Tabela 6, foi similar entre os dois genótipos de novilhas estudados, sendo ambas classificadas como vermelha levemente escura. Ao estudarem novilhos $\mathrm{C}$ e $\mathrm{N}$ e suas cruzas $\mathrm{F}_{1}$, RESTLE et al. (1995b) observaram que não houve diferença significativa entre os animais definidos e os meio sangues. Trabalhando com animais abatidos aos quatorze meses, RESTLE et al. (1995c) verificaram similaridade na coloração da carne entre $\mathrm{H}$ e $5 / 8 \mathrm{H}$ $3 / 8 \mathrm{~N}$, sendo de 4,37 e 4,87 pontos, respectivamente. Também com animais da mesma idade, RESTLE et al. (1997) verificaram grande semelhança entre animais $\mathrm{H}$ e $3 / 4 \mathrm{H} 1 / 4 \mathrm{~N}$, entretanto com valores indicando coloração mais escura $(2,67$ no $\mathrm{H}$ e 2,62 pontos nos cruzados), diferença que provavelmente pode ser explicada pelo fato que os animais do último trabalho não serem castrados.

No presente trabalho, a textura da carne foi similar $(P>0,10)$ entre os dois grupos de novilhas estudados, sendo ambas situadas entre levemente grosseira e fina. No entanto, CROUSE et al. (1989), trabalhando com o cruzamento de $\mathrm{H}$ e Brahman, constataram que a textura da carne piorou, à medida que houve incremento de sangue Bos indicus, obtendo valores de 5,$82 ; 5,68 ;$ e 5,84 pontos, respectivamente, para animais 1/4, 1/2 e 3/4 Brahman. RESTLE et al. (1995c) verificaram que, em animais $\mathrm{He} 5 / 8 \mathrm{H} 3 / 8 \mathrm{~N}$, a textura foi classificada como fina a muito fina, valor superior ao deste trabalho, que pode ser explicado, em parte, pela menor idade de abate dos animais, pouco mais de um ano. Também na Tabela 6 , observa-se que as novilhas $\mathrm{C}$ apresentaram marmoreio classificado entre leve mais e pequeno menos $(6,40$ pontos), enquanto nas cruzadas o marmoreio foi classificado como leve típico $(5,00$ pontos; $\mathrm{P}=0,1065)$. $\mathrm{O}$ coeficiente de correlação entre marmoreio e textura foi de $0,67(\mathrm{P}<0,05)$ e entre marmoreio e gordura subcutânea, de $0,65(\mathrm{P}<0,10)$, para estas últimas. Estes resultados são contrastantes com os verificados por outros autores, os quais citam grande efeito do vigor híbrido sobre a característica 
Rev. bras. zootec.

marmoreio da carne, sendo que a heterose pode chegar a 24,9\% no cruzamento entre Aberdeen Angus e Pardo Suiço (MARSHALL et al., 1987) e $25,8 \%$ entre C e N (VAZ, 1999). Segundo MARSHALL et al. (1987), a diferença deve-se ao efeito da alimentação pré-desmame, que ainda é bastante marcante em animais abatidos até os 24 meses, o que pode confirmar os resultados verificados por VAZ (1999), que também utilizou animais abatidos com essa idade. Os resultados do presente trabalho mostram que essa diferença pode desaparecer, quando o abate acontece em idade mais avançada, pois, neste estudo, as novilhas foram abatidas aos três anos de idade. Outra possível explicação pode estar ligada ao sexo dos animais.

As médias verificadas para maciez da carne (Tabela 6) mostram que o cruzamento não alterou essa importante característica da carne, a qual está sendo cada vez mais exigida pelos consumidores. Vários trabalhos têm demonstrado maior maciez na carne de taurinos em relação aos zebuínos (CROUSE et al., 1989; WHIPPLE et al., 1990; PEROBELLI et al., 1994; MOLETTA e RESTLE, 1996b; FLORES, 1997). Segundo CROUSE et al. (1989) e WHIPPLE et al. (1990), a menor maciez da carne de animais zebuínos deve-se à maior concentração de calpastatina no músculo desses animais.

Estudando os fatores associados à maciez da carne de animais $\mathrm{H}$ e Brahman, WHEELER et al. (1990) verificaram que os animais europeus apresentaram carne mais macia do que os zebuínos. RESTLE et al. (1997), estudando animais da raça $\mathrm{H}$ e suas cruzas com N, verificaram que os novilhos com $25 \%$ de sangue $\mathrm{N}$ apresentaram carne mais macia do que aqueles com $38 \%$ de sangue zebuíno. Os valores de 5,$8 ; 5,1 ; 5,0 ;$ e 4,5 pontos, respectivamente, para novilhos $\mathrm{H}, 5 / 8 \mathrm{H} 3 / 8 \mathrm{~N}, 1 / 2 \mathrm{H} 1 / 2 \mathrm{~N}$ e $1 / 4 \mathrm{H} 3 / 4 \mathrm{~N}$, foram obtidos por RESTLEet al. (1999), com animais abatidos aos 24 meses, mostrando que, quanto maior o grau de sangue $\mathrm{N}$ no genótipo dos novilhos, menor é a maciez da carne. O coeficiente de correlação entre maciez e gordura subcutânea foi de $0,56(\mathrm{P}<0,05)$ para as novilhas $\mathrm{C}$.

Também o valor observado na força necessária para corte das fibras da carne, medido pelo aparelho WB-Shear, foi similar entre os dois genótipos $(\mathrm{P}>0,10)$. O coeficiente de correlação entre valor do Shear e a maturidade fisiológica das novilhas $\mathrm{C}$ do presente trabalho foi de $0,86(\mathrm{P}<0,01)$ e entre valor do Shear e textura da carne, nas novilhas cruzadas, de 0,69 $(\mathrm{P}<0,05)$. Também ROCHA et al. (1997) verificaram alta correlação entre valor de Shear e textura da carne em animais abatidos aos quatorze meses de idade.

Estudando novilhos abatidos aos dois anos, oriundos do cruzamento dialelo entre C e N, VAZ (1999)

Tabela 6 - Média e desvio-padrão (DP) para cor, textura, marmoreio, características sensoriais e força para cizalhamento das fibras da carne (Shear)

Table 6 - Mean and standard error (DP) for color, texture, marbling, sensorial characteristic and shear value

\begin{tabular}{|c|c|c|c|c|c|}
\hline \multirow{2}{*}{$\begin{array}{l}\text { Característica } \\
\text { Characteristic }\end{array}$} & \multicolumn{2}{|c|}{$\mathrm{C}$} & \multicolumn{2}{|c|}{$3 / 4 \mathrm{C} 1 / 4 \mathrm{~N}$} & \multirow[t]{2}{*}{$P>F$} \\
\hline & $\begin{array}{l}\text { Média } \\
\text { Mean }\end{array}$ & DP & $\begin{array}{l}\text { Média } \\
\text { Mean }\end{array}$ & DP & \\
\hline $\begin{array}{l}\text { Cor, pontos }{ }^{1} \\
\text { Color, score }\end{array}$ & 3,46 & 0,16 & 3,11 & 0,21 & 0,1917 \\
\hline $\begin{array}{l}\text { Textura, pontos }{ }^{2} \\
\text { Texture, score }\end{array}$ & 3,67 & 0,29 & 3,33 & 0,37 & 0,4856 \\
\hline $\begin{array}{l}\text { Marmoreio, pontos } \\
\text { Marbling, score }^{3}\end{array}$ & 6,40 & 0,51 & 5,00 & 0,66 & 0,1065 \\
\hline $\begin{array}{l}\text { Maciez, pontos }{ }^{4} \\
\text { Tenderness, score }\end{array}$ & 6,48 & 0,22 & 6,19 & 0,28 & 0,4235 \\
\hline $\begin{array}{l}\text { Palatabilidade, pontos }{ }^{4} \\
\text { Flavor, score }\end{array}$ & 6,33 & 0,18 & 6,33 & 0,24 & 0,9999 \\
\hline $\begin{array}{l}\text { Suculência, pontos }{ }^{4} \\
\text { Juiciness, score }\end{array}$ & 6,18 & 0,17 & 5,67 & 0,22 & 0,0800 \\
\hline $\begin{array}{l}\text { Shear, kg } \\
\text { Shear, value }\end{array}$ & 5,99 & 0,42 & 6,24 & 0,54 & 0,7253 \\
\hline
\end{tabular}


observou maciez semelhante entre $\mathrm{C}$ ( 6,76 pontos) e 3/4 C 1/4 N (6,36 pontos). Embora DeROUEN et al. (1992) alertem que a maciez da carne diminua com a inclusão de sangue zebuíno no cruzamento, WHEELER et al. (1996) citam que os efeitos heteróticos das raças zebuínas sobre a qualidade da carcaça são positivos e a queda de maciez da carne em animais cruzados é de pouca magnitude e importância prática.

Verifica-se na Tabela 6 que a palatabilidade da carne foi a mesma ( 6,33 pontos) entre os dois genótipos estudados, porém apenas nas novilhas puras existiu correlação significativa entre esta característica e gordura na carcaça, sendo o $\mathrm{r}=0,51 \quad(\mathrm{P}<0,10)$. PEROBELLI et al. (1994), estudando vacas de descarte das raças $\mathrm{C}$ e $\mathrm{N}$, verificaram que a palatabilidade da carne das últimas foi superior em relação à carne das vacas $\mathrm{C}$, o que pode ter sido reflexo de melhor acabamento e de maior marmoreio que as vacas $\mathrm{N}$ obtiveram em relação às européias. Já RESTLE et al. (1997), estudando animais $\mathrm{H}$ e suas cruzas com $\mathrm{N}$, observaram que os novilhos puros $\mathrm{H}$ e $3 / 4 \mathrm{H} 1 / 4 \mathrm{~N}$ apresentaram carne mais palatável do que os $5 / 8 \mathrm{H}$ $3 / 8 \mathrm{~N}$, com valores para palatabilidade de $6,34,6,85$ e 5,42, respectivamente. No estudo realizado por VAZ (1999), foi verificado que a palatabilidade da carne de novilhos da raça $\mathrm{C}$ ( 5,81 pontos) foi melhor em relação aos animais da raça $\mathrm{N}$ (5,42 pontos), segundo este autor, em parte, estes resultados provavelmente devem-se ao fato de existir boa correlação fenotípica desta característica com as demais características sensoriais da carne.

$\mathrm{Na}$ Tabela 6 observa-se que a suculência da carne foi maior nas novilhas $\mathrm{C}(\mathrm{P}=0,0800)$ do que nas cruzadas. A provável explicação para tal fato pode ser devida a fatores de estresse pré-abate nas novilhas com participação de sangue $\mathrm{N}$ no genótipo. No trabalho realizado por RESTLE et al. (1997), verificou-se que os animais com $38 \%$ de sangue $\mathrm{N}$ obtiveram suculência inferior aos animais com $25 \%$ de sangue $\mathrm{N}$.

As características maciez, palatabilidade, suculência e também os valores de Shear mostram que as novilhas dos dois grupos genéticos, mesmo abatidas aos três anos de idade, apresentam carne similar à de novilhos abatidos aos dois anos (RESTLE et al., 1995b; RESTLE et al., 1999; VAZ, 1999) e bastante superior à carne de vacas de descarte (PEROBELLI et al., 1994).

\section{Conclusões}

Novilhas dos genótipos C e 3/4 C 1/4 N, abatidas aos três anos de idade, não diferiram em peso de abate, rendimento e peso de carcaça, espessura de gordura, conformação, e medidas de desenvolvimento de carcaça, entretanto, novilhas $\mathrm{C}$ apresentaram maior porcentagem de serrote e perímetro de braço do que novilhas $3 / 4 \mathrm{C} 1 / 4 \mathrm{~N}$.

Apesar de as novilhas 3/4 C 1/4 N terem apresentado carne de menor suculência que novilhas $\mathrm{C}$, as demais características de qualidade de carcaça e de carne foram semelhantes entre os dois genótipos.

Outros estudos precisam ser conduzidos no Brasil, visando gerar resultados referentes ao efeito da idade ao abate e do sexo sobre as características de qualidade da carcaça e carne.

\section{Referências Bibliográficas}

BERG, R.T., BUTTERFIELD, R.M. 1976. New concepts of cattle growth. Sydney: Sydney University Press. 240p.

CROUSE, J.D., CUNDIFF, L.V., KOCH, R.M. et al. 1989. Comparisons of Bos indicus and Bos taurus inheritance for carcass beef characteristics and meat palatability. J. Anim. Sci., 67(10):2661-2668.

DeROUEN, S.M., FRANKE, D.E., BIDNER, T.D. et al. 1992. Direct and maternal genetic effects for carcass traits in beef cattle. J. Anim. Sci., 70(12):3677-3685.

FLORES, J.L.C. Desempenho em confinamento e características de carcaça e da carne de bovinos de diferentes grupos genéticos abatidos aos quatorze meses. Santa Maria, RS: UFSM, 1997. 109p. Dissertação (Mestrado em Zootecnia) - Universidade Federal de Santa Maria, 1997.

FLORES, J.L.C., RESTLE, J., ALVES FILHO, D.C. et al. Características quantitativas da carcaça de bovinos de diferentes grupos genéticos abatidos aos quatorze meses. In: REUNIÃO ANUAL DA SOCIEDADE BRASILEIRA DE ZOOTECNIA, 36., 1999. Porto Alegre. Anais... Porto Alegre: SBZ, 1999. p.148.

GALVÃO, J.G., FONTES, C.A.A., PIRES, C.C. 1991. Características e composição física da carcaça de bovinos nãocastrados, abatidos em três estágios de maturidade (Estudo II) de três grupos raciais. R. Soc. Bras. Zootec., 20(5):503-512.

HANKINS, O.G., HOWE, P.E. 1946. Estimation of the composition of beef carcasses and cuts. Washington: United State Department of Agriculture (Technical Bulletin, 926).

JUNQUEIRA, J.O.B., VELLOSO, L., FELÍCIO, P.E. 1998. Desempenho, rendimentos de carcaça e cortes de animais, machos e fêmeas, mestiços Marchigiana x Nelore, terminados em confinamento. Rev. bras. zootec., 27(6):1199-1205.

KOGER, M. 1980. Effective crossbreeding systems utilizing zebu cattle. J. Anim. Sci., 50(6):1213-1220.

LUCHIARI FILHO, A., LEME, P.R., RAZOOK, A.G. et al. 1989. Características de carcaça e rendimento de porção comestível de machos Nelore comparados a cruzados $\left(\mathrm{F}_{1}\right)$ obtidos do acasalamento de touros das raças Canchim, Santa 
Rev. bras. zootec.

Gertrudis, Caracu, Holandês e Suiço com fêmeas Nelore. II. Animais castrados terminados a pasto. Bol. Ind. Anim., 46(1):27-35.

MARSHALL, T.T., HARGROVE, D.D., OLSON, T.A . 1987. Heterosis and additive breed effects on feedlot and carcass traits from crossing Angus and Brown Swiss. J. Anim. Sci., 64(5):1332-1339.

MOLETTA, J.L., RESTLE, J. 1996a. Características de carcaça de novilhos de diferentes grupos genéticos terminados em confinamento. R. Soc. Bras. Zootec., 26(5):866-875.

MOLETTA, J.L., RESTLE, J. 1996b. Influência do grupo genético sobre características qualitativas da carne de novilhos. R. Soc. Bras. Zootec., 26(5):866-875.

MULLER, L. 1987. Normas para avaliação de carcaça e concurso de carcaças de novilhos. 2.ed. Santa Maria: UFSM. $31 \mathrm{p}$.

PEACOCK, F.M., PALMER, AZ., CARPENTER, J.W. et al. 1979. Breed and heterosis effects on carcass characteristics of Angus, Brahman, Charolais and crossbred steers. J. Anim. Sci., 49(2):391-397.

PEROBELLI, Z.V., MULLER, L., RESTLE, J. 1994. Estudo da qualidade das carcaças e da carne de vacas de descarte de dois grupos genéticos. Ciência Rural, 24(3):613-616.

PEROBELLI, Z.V., RESTLE, J., MULLER, L. 1995. Estudo das carcaças de vacas de descarte das raças Charolês e Nelore. Pesq. Agropec. Bras., 30(3):409-412.

PEROTTO, D., CUBAS, A.C., MOLETTA, J.L. et al. 1999. Peso ao nascimento e à desmama e ganho de peso do nascimento à desmama de bovinos Charolês, Caracu e cruzamentos recíprocos. Rev. bras. zootec., 27(4):730-737.

RESTLE, J., FELTEN, H.G., VAZ, F.N. Efeito de raça e heterose para características quantitativas da carcaça de novilhos de 24 meses terminados em confinamento. In: REUNIÓN LATINOAMERICANA DE PRODUCCIÓN ANIMAL, 14., 1995. Mar del Plata. Memórias... Balcarce: ALPA, 1995a. p.857-859.

RESTLE, J., FELTEN, H.G., VAZ, F.N. et al. Efeito de raça e heterose para qualidade da carcaça e da carne de novilhos terminados em confinamento. In: REUNIÓN LATINOAMERICANA DE PRODUCCIÓN ANIMAL, 14., 1995. Mar del Plata. Memórias... Balcarce: ALPA, 1995b. p.854-856.

RESTLE, J., KEPLIN, L.A.S., VAZ, F.N. 1997. Características quantitativas da carcaça de novilhos Charolês, abatidos com diferentes pesos. Pesq. Agrop. Bras., 32(8):851-856.
RESTLE, J., SILVA, L.C.R., MULLER, L. et al. Características de carcaça de vacas Hereford e Charolês terminadas em regime de confinamento. In: REUNIÃO ANUAL DA SOCIEDADE BRASILEIRA DE ZOOTECNIA, 27., 1990. Campinas. Anais... Campinas: SBZ, 1990. p.353.

RESTLE, J., VAZ, F.N., QUADROS, A R.B. et al. 1999. Características de carcaça e da carne de novilhos de diferentes genótipos de Hereford x Nelore. Rev. bras. zootec., 28(6):1245-1251.

RESTLE, J., VAZ, F.N., VAZ, R.Z. Qualidade da carcaça e da carne de novilhos de três grupos genéticos abatidos aos quatorze meses de idade. In: REUNIÃO ANUAL DA SOCIEDADE BRASILEIRA DE ZOOTECNIA, 32., 1995. Brasília. Anais... Brasília: SBZ, 1995. p.647-649.

ROCHA, J.B.T., PEROTTONI, J. RESTLE, J. et al. Qualidade da carne de animais inteiros de dois grupos genéticos, abatidos aos quatorze meses de idade. In: REUNIÃO ANUAL DA SOCIEDADE BRASILEIRA DE ZOOTECNIA, 34., 1997. Juiz de Fora. Anais... Juiz de Fora: SBZ, 1997. p.199-201.

VAZ, F.N. Cruzamento alternado das raças Charolês e Nelore: características de carcaça e da carne de novilhos abatidos aos dois anos. Santa Maria: UFSM, 1999. 58p. Dissertação (Mestrado em Zootecnia) - Universidade Federal de Santa Maria, 1999.

VAZ, F.N., ROSO, C., VAZ, R.Z. 1999. Gerenciamento visando a eficiência econômica da pecuária de corte. In: RESTLE, J. (Ed.) Confinamento, pastagens e suplementação para produção de bovinos de corte. Santa Maria: UFSM. p.233-259.

WHEELER, T.L., SAVELL, J.W., CROSS, H.R. et al.1990. Mechanisms associated with the variation in tenderness of meat from Brahman and Hereford cattle. J. Anim. Sci., 68(12):4206-4220.

WHEELER, T.L., CUNDIFF, L.V., KOCH, R.M. 1996. Characterization of biological types of cattle (Cycle IV): carcass traits and longissimus palatability. J. Anim. Sci., 74(5):1023-1035.

WHIPPLE, G., KOOHMARAIE, M., DIKEMAN, M.E.et al. 1990. Evaluation of attributes that affect longissimus muscle tenderness in Bos taurus and Bos indicus cattle. J. Anim. Sci., 68(9):2716-2728.

Recebido em: 07/08/00

Aceito em: 11/12/00 